\title{
Information Transparency for Health Care Consumers: Clear, but Effective?
}

\author{
J. Michael McWilliams, $M D, P h D^{1,2}$ \\ 'Department of Health Care Policy, Harvard Medical School, Boston, MA, USA; ${ }^{2}$ Division of General Internal Medicine and Primary Care, \\ Department of Medicine, Brigham and Women's Hospital and Harvard Medical School, Boston, MA, USA.
}

$\mathrm{J}$ Gen Intern Med 28(11):1387-8

DOI: $10.1007 / \mathrm{s} 11606-013-2517-y$

() Society of General Internal Medicine 2013

$\mathrm{H}$ ealth care information reported to the public could be used by a variety of stakeholders, but a primary purpose of transparency initiatives is to elicit a consumer (i.e., patient) response that is sufficiently strong to trigger marketbased solutions to our health care problems. The idea is certainly attractive. Provide patients with price and quality information on a variety of health plans, providers, and services. Give them skin in the game in the form of high deductibles or fixed vouchers so they have financial incentives to choose high-value options. And the rest will follow - healthy competition, better quality, and lower costs.

While the logic follows standard consumer theory in economics, we know that health care markets often do not. How much then should our health care system rely on patient responses to information to achieve its goals? A realistic assessment of the promise of transparency should consider what we know about patient responses to the information they already have, the types of decisions that might be influenced by the availability of more information, and the relative merits of complementary strategies to mitigate information problems in health care.

Despite the abundance of available information on benefits, premiums, and cost-sharing in Medicare Advantage and Part D plans, Medicare beneficiaries regularly make suboptimal enrollment decisions. ${ }^{1,2}$ Type in a Boston zip code on the Medicare find-a-plan website and you will find a plethora of choices. Seniors can pick either traditional Medicare, in which case they must choose from 27 Part D drug plans (not to mention a variety of supplemental Medigap plans), or Medicare Advantage, in which case they must choose from 14 plans. The website deserves high marks for transparency, clearly describing the menu of options. Focusing on the Medicare Advantage plans, there are seven dimensions with a total of 17 specific attributes summarized for each plan. There are tradeoffs to be weighed between premiums, covered services, total average out-of-pocket costs, and network restrictions. Twelve of the 14 plans are given 4.5 out of 5 stars for quality of care. The two with fewer stars are sponsored by the AARP, a trusted source of

Published online June 14, 2013 information for seniors. Confused by any of this? Click on the "?" icons for more information.

When choosing from such numerous and complex options, it is not surprising that consumers often resort to heuristics (e.g., picking the lowest premium plan even if the benefits are paltry), or fail to make any choice at all and default into an option offering lower average value (e.g., traditional Medicare). Thus, there is a need to package complex information into signals that can more reliably direct consumers to the best options. For example, various plan features could be collapsed into a single star rating that reflects overall value. But what's transparent about that?

Even when the availability of potentially better choices is made clear, health care consumers often do not make them. The Medicare Part D low-income subsidy program offers a particularly striking example. Despite the essentially free prescription drug coverage it affords and outreach efforts by the Social Security Administration, more than half of eligible beneficiaries fail to take up the subsidy. ${ }^{3}$ The response of commercial plan enrollees to tiering of provider networks on the basis of quality and efficiency has been similarly weak. ${ }^{4}$ Lack of awareness, low educational attainment, poor health literacy, and limited cognitive abilities have been implicated in explaining particularly blunted responsiveness to options that could improve patients' health and financial well-being. These characteristics are more common among the chronically ill, whose care accounts for the majority of health care spending. If health care consumers do not consistently reward value in cases where information is clear now, should we expect policies that rely on their choices in a world of more information to foster value-based competition? Is this the way to bend the cost curve?

Even among health care shoppers with the motivation and wherewithal to access and process available information on price and quality, transparency could have unintended consequences. Price transparency could actually increase demand for higher priced rather than lower priced plans and providers. Specifically, patients may extrapolate from their experience in better functioning markets - where price and quality are equally visible and positively correlated - to health care markets where quality is so challenging to measure and convey. Unable to judge quality as well as prices, patients could migrate to providers and plans with higher prices (and thus higher perceived quality), but receive care that is not 
necessarily better. Alternatively, if health care prices and quality are positively correlated, and if low-income groups trade off higher quality for lower prices, price transparency could exacerbate longstanding health disparities.

Finally, any gains achieved by alerting patients to higher rated plans and providers could be partially or completely offset by switching costs, including duplicative start-up testing and data collection, the time costs to patients of learning new practices, and the clinical consequences of disruptions in care continuity. Strategies that rely on consumers to shop and switch could be targeted to one-time procedures and specialty services, but would be limited in scope without other efforts to address inefficiencies in longitudinal care.

Recognizing that the provision of information alone is unlikely to affect consumer behavior in health care substantially, proponents of market-based transparency strategies generally favor coupling the information with financial or non-financial nudges. These nudges could take the form of tier-based, price-based, or value-based cost sharing, insurance exchanges or employers actively guiding consumers to the best plans, or default pathways supporting high-value options. Packaging information into more effective signals is also a type of nudge. Nudging, however, is not an extension of transparency. Rather, it is a form of agency. Moreover, if the interests of the agents in the health care system - governments, employers, insurers, and providers - are aligned with the interests of patients and society, in principle there may be no need for transparency to consumers to achieve a shared set of goals. As long as the incentives are right, these agents, better equipped to process information on price and quality, should transmit information to patients in the form of financial or nonfinancial nudges that are clear, strong, and welfare-enhancing.

For example, responding to new payment incentives in the Blue Cross Blue Shield of Massachusetts' Alternative Quality Contract, participating provider organizations successfully steered patients to lower priced providers for imaging, procedures, and tests. ${ }^{5}$ The resulting savings were substantial among the chronically ill. The nudge? Referrals. There was no need for patients to access price data. The providers, with knowledge of prices elsewhere in the market, did it for them. The patients went where they were referred.

If nudges are needed to enhance consumer responses to health care information, the goals of our health care system may be better served by transparency efforts conceived as complements to payment reforms, delivery system transformation, and regulatory policies, as opposed to detached market-based initiatives. There is no question that the health care system is in need of better information, but public information systems could have limited or counterproductive effects if they are constructed without consideration of other strategies to improve quality and control spending. Instead of simply releasing information in the spirit of transparency or consumerism, policymakers might first ask, what information do insurers and providers need to support and refine new payment systems and value-based coverage designs that align financial incentives with the social goals of better health and lower costs? What data do purchasers need to reward insurers and providers for achieving these goals by steering patients to them? What combination of regulation and price data could stimulate price competition in less competitive markets where transparency might actually increase prices?

In particular, sound policy governing the availability of health care information should consider foremost the physicianpatient interaction, where no amount of transparency can close the information gap (due to vast differences in education and training) and where the nudges are most powerful ("Doc, what do I do?"). The decisions that determine the bulk of health care spending are those that are made in the office and on the wards, when the patient is at a loss for direction, when the deductible has been spent, when skin in the game just isn't fair. Given what we know about consumer responses to health care information, it's a stretch to expect strategies predicated on transparency, shopping, and switching to drive the cost-effectiveness of those decisions a meaningful distance. If other means of influencing patient behavior are necessary to facilitate such strategies anyway, the natural starting point is to get provider payment right and develop the information systems for providers to get the nudges right. ${ }^{6}$ If that much is accomplished, and it is a lot, consumers may find the health care system no more transparent, but they might more consistently receive five-star care.

The work of JM McWilliams is supported by grants from the Beeson Career Development Award Program (National Institute on Aging K08 AG038354 and the American Federation for Aging Research), the Doris Duke Charitable Foundation (Clinical Scientist Development Award \#2010053), and National Institute on Aging (P01 AG032952).

Conflict of Interest: Dr. McWilliams has conflicts of interest to disclose.

Corresponding Author: J. Michael McWilliams, $M D, P h D$; Department of Health Care Policy, Harvard Medical School, 180 Longwood Ave., Boston, MA 02115, USA (e-mail: mcwilliams@hcp.med.harvard.edu).

\section{REFERENCES}

1. Abaluck J, Gruber J. Choice inconsistencies among the elderly: evidence from plan choice in the medicare part D program. Am Econ Rev. 2011;101:1180-210.

2. McWilliams JM, Afendulis CC, McGuire TG, Landon BE. Complex Medicare Advantage choices may overwhelm seniors-especially those with impaired decision making. Health Aff (Millwood). 2011;30:1786-94.

3. Kuye IO, Frank RG, McWilliams JM. Cognition and take-up of subsidized drug benefits by Medicare beneficiaries. JAMA Intern Med 2013; (Epub ahead of print) doi:10.1001/jamainternmed.2013.845.

4. Sinaiko, AD. Tiered provider networks as a strategy to improve health care quality and efficiency. Expert Voices in Health Care Policy. National Institute for Health Care Management. 2012. (Accessed April 22, 2013, at http://nihcm.org/images/stories/EV-Sinaiko-2012.pdf.)

5. Song Z, Safran DG, Landon BE, et al. The 'Alternative Quality Contract', based on a global budget, lowered Medical spending and improved quality. Health Aff (Millwood). 2012;31:1885-94.

6. Patel MS, Volpp KG. Leveraging insights from behavioral economics to increase the value of health-care service provision. J Gen Intern Med. 2012;27:1544-7. 